\title{
SURGICAL THERAPY FOR ABNORMALITIES OF THE URINARY SPHINCTER IN THE FEMALE ${ }^{1}$
}

\author{
By JACK LAPIDES, M.D. \\ From the Section of Urology, Department of Surgery, University of Michigan Medical School, \\ Ann Arbor, Michigan and Wayne County General Hospital, Eloise, Michigan
}

THE ability to initiate and terminate micturition in a normal fashion and to maintain continence between voidings depends upon an intact corticoregulatory tract and an adequate urinary sphincter (Lapides, 1962). It has been demonstrated (Lapides et al., 1960 a; Woodburne, 1960) that the urinary sphincter is a tubular structure (Fig. 1) approximately $3 \mathrm{~cm}$. long in both the young male and female adult. The proximal end of the tube is continuous with the bladder fundus while the distal end merges into the bulbous urethra in the male, and the terminal centimetre of vaginal urethra in the female (Lyon and Smith, 1963).

The tubular sphincter is lined by a mucous membrane consisting primarily of transitional epithelium and possesses a heavy outer coat of smooth muscle (Fig. 2). The smooth muscle fibres are direct extensions of the detrusor meshwork and are primarily longitudinal in nature. Unusually heavy concentrations of elastic tissue occur submucosally and between the longitudinal muscle fibres. The elastic fibres are found along the entire length of the urinary sphincter and are disposed in a circular fashion.

While the fundus of the bladder is acting as a reservoir and storing urine, the lumen of the urinary sphincter is constricted by the inherent tonic compressing action of the smooth muscle and elastic fibres in its wall. Urine in the bladder is prevented from flowing through the conduit by the tightly apposed surfaces of the turgid urethral mucous membrane. The sphincteric action of the posterior urethra per se is quite efficient provided the intravesical pressure is low to moderate.

When intravesical pressure rises to high levels the effectiveness of the posterior urethra must be increased in order to prevent leaking. This is readily accomplished by the activity of the striated muscles of the urogenital diaphragm and levator ani (Fig. 3) which compress and elongate the urinary sphincter. Both of these actions have been found to enhance urinary continence. The circumferential compression is applied mainly to the distal $2 \mathrm{~cm}$. of the urinary sphincter.

When the bladder converts from a storage to an evacuating organ, the urinary sphincter changes its configuration from an elongated, narrow conduit with obliterated lumen to a short, wide tube with a funnelled opening and a wide lumen (Fig. 3). The transformation occurs through relaxation of the periurethral striated muscle and active contraction of the detrusorurethral smooth muscle sheet. Because of this activity the resistance of the urinary sphincter is markedly decreased and the bladder can empty itself readily at low pressures.

\section{PHYSIOPATHOLOGY OF URINARY INCONTINENCE}

Incontinence of urine can result from abnormalities of the nerve tracts concerned with micturition or from disorders of the urinary sphincter (Zimmerman and Levine, 1964). Since most cases of neurogenic incontinence are not amenable to surgical therapy, the present discussion will be limited to lesions of the urinary sphincter. This implies that incontinence due to lesions of the periurethral striated muscle (so-called external urethral sphincter) will also be deleted since most of these abnormalities are due to motor paralysis. Defects in the tubular sphincter or posterior urethra can result in leaking of urine ranging from a constant drip to loss of a few

${ }^{1}$ Read at the Twenty-first Annual Meeting of the British Association of Urological Surgeons at London, June 1965.

$6 \mathrm{~A}$ 


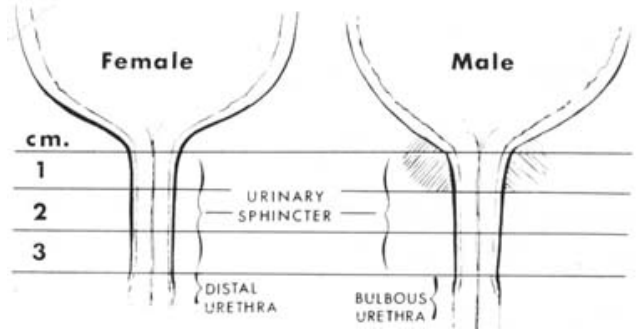

Frg. 1

The urinary sphincter is $3 \mathrm{~cm}$. long in both the young male and female adult.

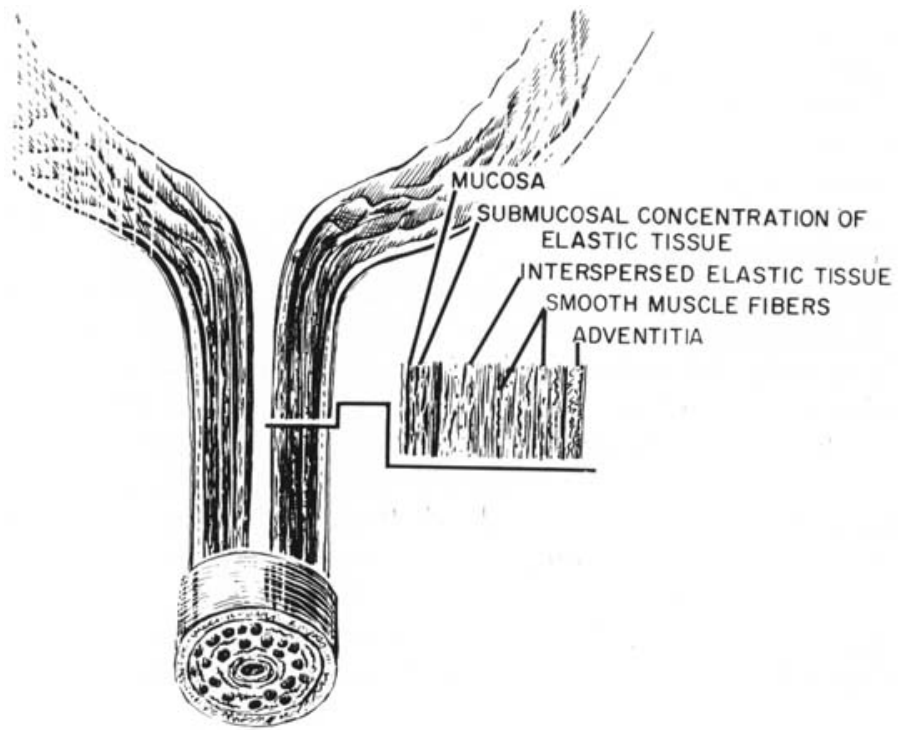

FiG. 2

Cross-section of the urinary sphincter illustrating distribution of elastic and smooth muscle fibres.

\section{Dynamics of Urinary Sphincter}

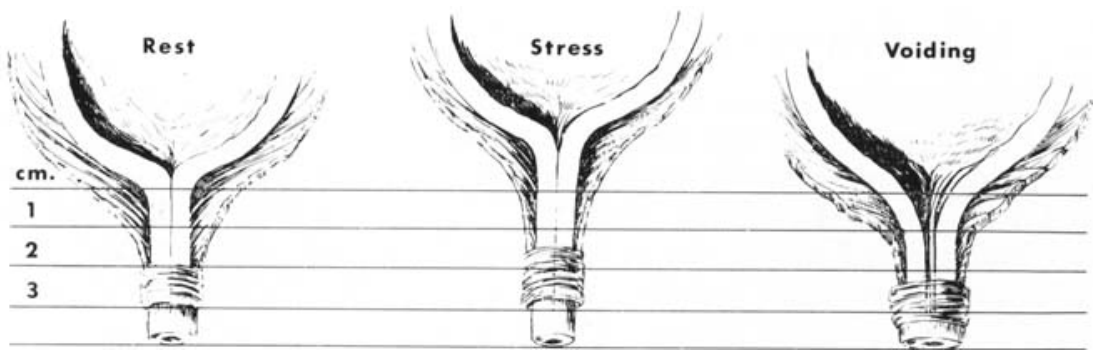

FIG. 3

Attitudes of the urinary sphincter when the individual is at rest, straining and micturating. 
drops only on marked exertion. Experimental (Lapides, 1958) and clinical (Lapides et al., 1960 b) data indicate that the degree of continence varies directly with the length of normal intact tubular sphincter. Thus a patient with only a short segment of normally functioning urethra will wet herself more readily than will a female with a longer segment.

\section{TYPES OF INCOMPETENT URINARY SPHINCTERS}

$A$. Drooping Urethra.-Most cases of non-neurogenic and non-iatrogenic urinary incontinence in the adult female are associated with a decrease in length of urinary sphincter, occurring when the patient assumes the standing position (Fig. 4). The shortening of the tubular sphincter is in the form of a drooping or telescoping presumably due to lack of adequate support of the urethrovesical junction by musculofascial elements. The dysfunction can be compared to the sagging of trousers not adequately supported by braces when the individual assumes the standing position. These women demonstrate an actual decrease in urethral length which can be measured readily with a graduated retention catheter.

B. Defective Urethra.-(1) Acquired.-Some patients with a history of transvaginal or transurethral trauma will exhibit urinary incontinence despite a urinary sphincter which is normal in length by measurement. Endoscopic evaluation in these individuals will reveal a defect of varying size in the wall of the urethra (Fig. 5) causing a decrease in functional rather than actual length of tubular sphincter. A tight sphincter requires a complete ring of normal smooth muscle and elastic tissue. A break in this ring occasioned by the replacement of a segment of muscle with scar tissue or a fistula will result in flaccidity of the involved segment with a decrease in functional length of the urinary sphincter equivalent to the dimension of the diseased segment.

(2) Congenital.-The frank case of epispadias is an obvious cause for incontinence in the child. The urethra fails to close anteriorly and thus there is zero length of functioning sphincter present. However, there are female children with apparently intact urethras who demonstrate the same type of dripping incontinence as the overt epispadiac. Careful examination of these girls will usually disclose some of the stigmata associated with bladder exstrophy and epispadias, such as varying degrees of separation of the symphysis, bifid clitoris and abnormalities of the introitus. The urinary sphincter will appear to be patulous and short. It has been postulated that these urinary sphincters are incompetent because of congenitally defective tissue in the roof of the urethra.

$C$. Drooping, Defective Urethra.-A third category includes the adult females who demonstrate a combination of the two lesions previously described, namely, a decrease in actual length of.the urethra as well as a defect in its wall (Fig. 6).

\section{DIAGNOSIS OF SPHINCTER LESION}

Since urinary incontinence varies in type and xtiology, it is mandatory that a thorough urological examination be performed prior to the undertaking of any therapy. The diagnostic armamentarium must include pyelography, cystoscopy, urethroscopy, and cystometry. Measurement of urethral length in the supine and erect positions and the urecholine supersensitivity test (Lapides et al., 1962) should be part of the cystometric examination.

The differential diagnosis of urinary incontinence includes such types as stress, urge and dripping; continuous and intermittent; or partial and complete. Possible causes for urinary incontinence are the various neurogenic bladders such as the uninhibited, reflex, motor paralytic, sensory paralytic, autonomous and combinations thereof; the urothelial-vaginal fistulas, as for example, the ureterovaginal, vesicovaginal, and urethrovaginal; the congenital anomalies 

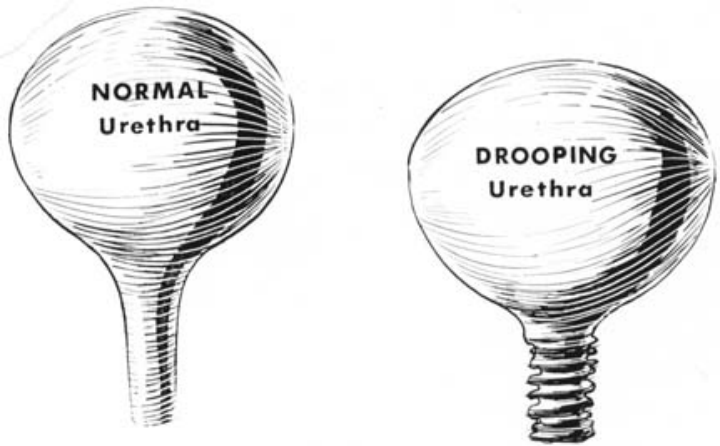

Fig. 4

Most cases of stress incontinence are associated with a sagging of the urethra in the erect position.
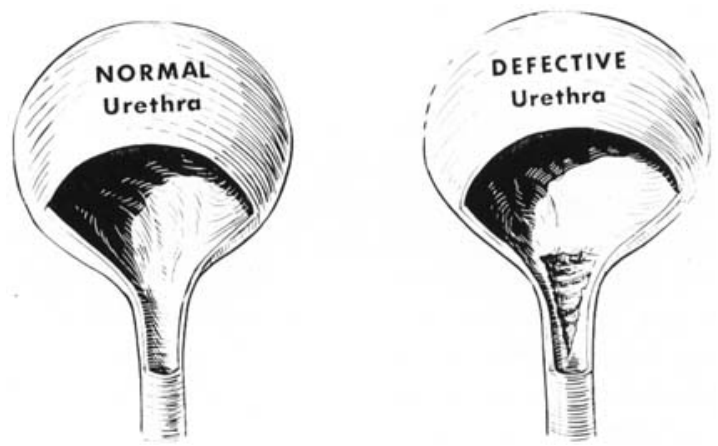

FiG. 5

Traumatic defects in the wall of the urethra may result in urinary incontinence by decreasing functional length.
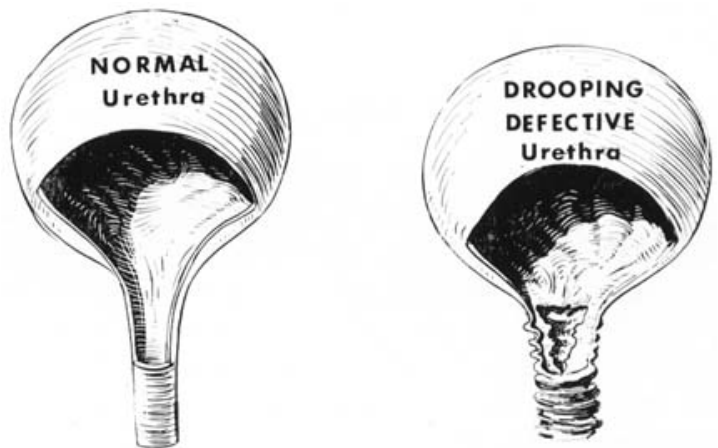

Fig. 6

Some patients with urinary incontinence may demonstrate both a drooping of the urethra as well as a defect in its wall. 
ectopic ureter and epispadias; the drooping urethra; the defective urethra; urinary tract infection; and psychogenic difficulties.

It is firmly believed that surgeons not trained and equipped to carry out all the diagnostic examinations should refrain from performing therapeutic procedures for urinary incontinence; for it is only by adhering to this dictum that much unnecessary operating, expense, and sorrow to both patient and physician will be avoided.

\section{SURGICAL THERAPY}

A. Drooping Urethra.-All cases of urinary incontinence due to a shortening of the urethra in the standing position can be completely alleviated by elongating the urethra and immobilising it in this state. This is best accomplished by a simple retropubic procedure, anterior urethropexy (Lapides, 1961), designed specifically for attaining the desired objectives. In essence the urethra is approached via a low suprapubic transverse incision (Fig. 7, 1) and its roof or anterior wall fixed to the periosteum of the symphysis with three to four pairs of heavy, chromic catgut sutures (Fig. 7, 2 to 8 ). The adventitia of the urethra should be exposed to view by bluntly dissecting away the overlying fat in order to make certain that the fixing suture pierces the entire wall of the urethra and incorporates about $1 \mathrm{~cm}$. of tissue in its bite. It is expected that the suture will enter the lumen of the urethra. An additional aid in securing adherence of the urethra to the periosteum is scarification of the adventitia with a scalpel blade.

Cystopexy and urethropexy techniques which do not incorporate lengthening of the urethra along with the fixation result in failure to alleviate the urinary incontinence in many instances. During the past five years fifteen patients with a history of urinary incontinence persisting after a Marshall-Marchetti procedure (Marshall et al., 1949) have been examined and explored surgically. All of the women were found to have a urethra which decreased to less than $3 \mathrm{~cm}$. length in the erect position. On exposing the retropubic area at operation and dissecting free the bladder and urethra from the symphysis (Fig. 8,2), it was noted that it was primarily the bladder which had'been sutured to the symphysis pubis rather than the urethra which was still collapsed distal to the area of fixation (Fig. 8, 1). Treatment for these patients consisted of freeing the bladder and urethra from the periosteum of the symphysis by sharp dissection (Fig. 8, 2), and then performing the conventional anterior urethropexy (Fig. 8, 3 and 4). Figure 8, 1, portrays the incorrect method and Figure 8, 4, the correct technique for curing stress incontinence due to a drooping urethra. Incidentally, all of the patients were markedly improved by re-operation.

Anterior colporrhaphy and other transvaginal procedures for treating urinary incontinence by buttressing the posterior wall of the urethra are contraindicated because $(a)$ the purpose of the operations is not in accord with the physiopathology of the urinary incontinence, $(b)$ only a portion of the patients are inadvertently helped by the surgery, and $(c)$ many of the patients are thrown into post-operative urinary retention for periods of time varying from several weeks to permanent retention. Comparison of urethral resistance following anterior colporrhaphy and anterior urethropexy performed on the same and different patients (Lapides and Anderson, unpublished data, 1965) reveals that anterior colporrhaphy compresses the urethra primarily at the urethrovesical junction whereas anterior urethropexy produces the greatest resistance in the mid $2 \mathrm{~cm}$. of urethra--the portion of urinary sphincter normally demonstrating the greatest pressure. Thus the urinary retention following anterior colporrhaphy is due to fixation of the urethrovesical junction by sutures taken too tightly at the bladder outlet. The constriction prevents the urethrovesical opening from being widened into a funnel by the detrusor-urethral muscle sheet-in essence the same effect as that produced by a vesical neck contracture of congenital or inflammatory origin.

Most of the patients will gradually regain the ability to empty the bladder as the catgut sutures undergo dissolution. The recovery process can be accelerated in some of the women 

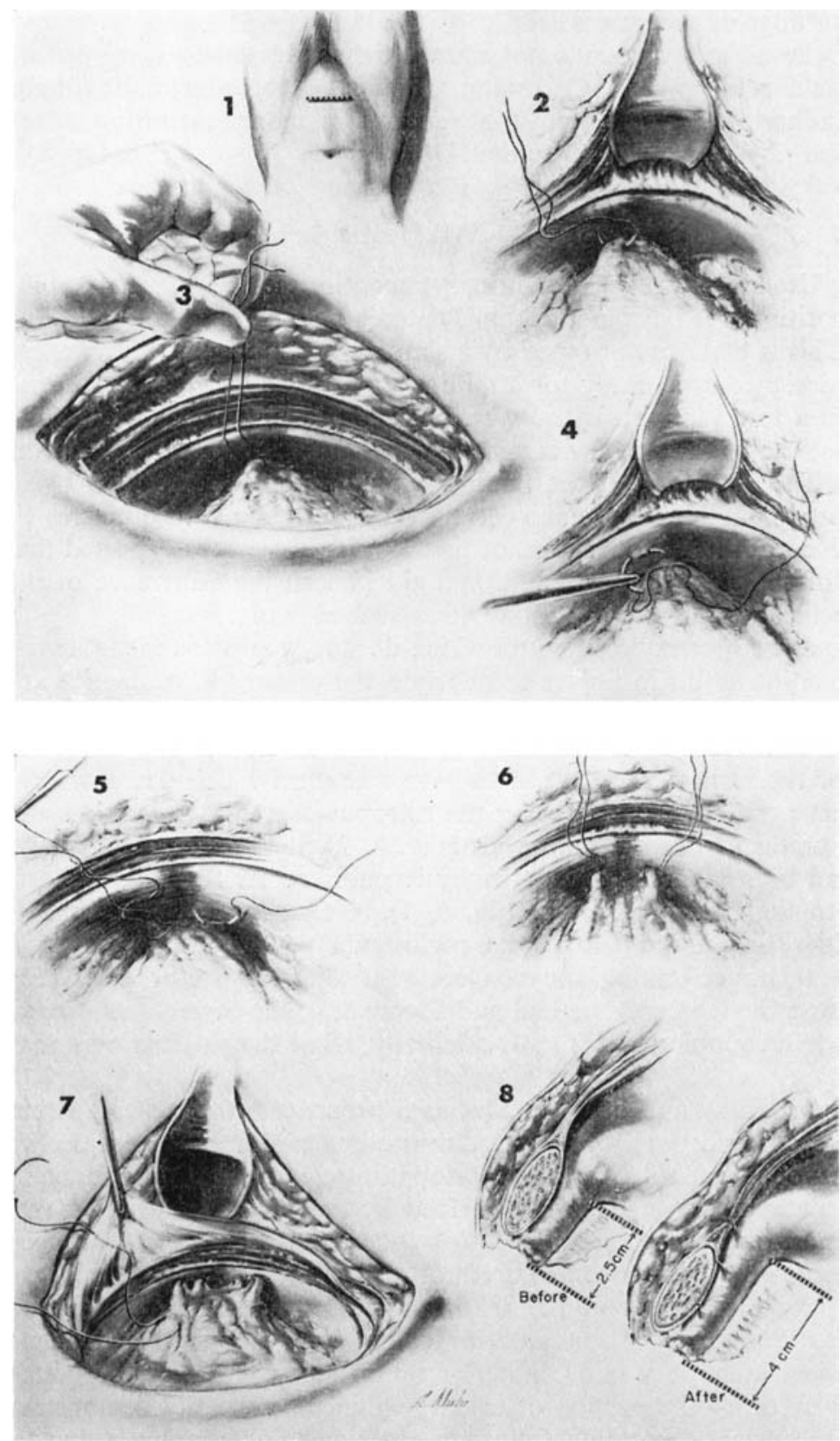

FIG. 7

Urinary incontinence caused by a drooping urethra is cured by elongating the urethra and fixing it to the symphysis in the stretched state. 
with the use of an appropriate bethanechol chloride regimen (Lapides, 1964). A few patients will persist in their urinary retention and will require interruption of the immobilised ring at the urethrovesical junction and insertion of a flap of normal bladder as accomplished by the Bradford Young type of vesical neck plasty (Young and Niebel, 1958).

B. Defective Urethra.-When urinary incontinence is due to a defect in the wall of the tubular sphincter, the basic principle of therapy is to excise the defect and reapproximate normal urethral wall to normal urethral wall so as to re-establish normal tonicity along an adequate length of urethra (Lapides, 1961). If the defect is in the floor of the urethra and the anterior

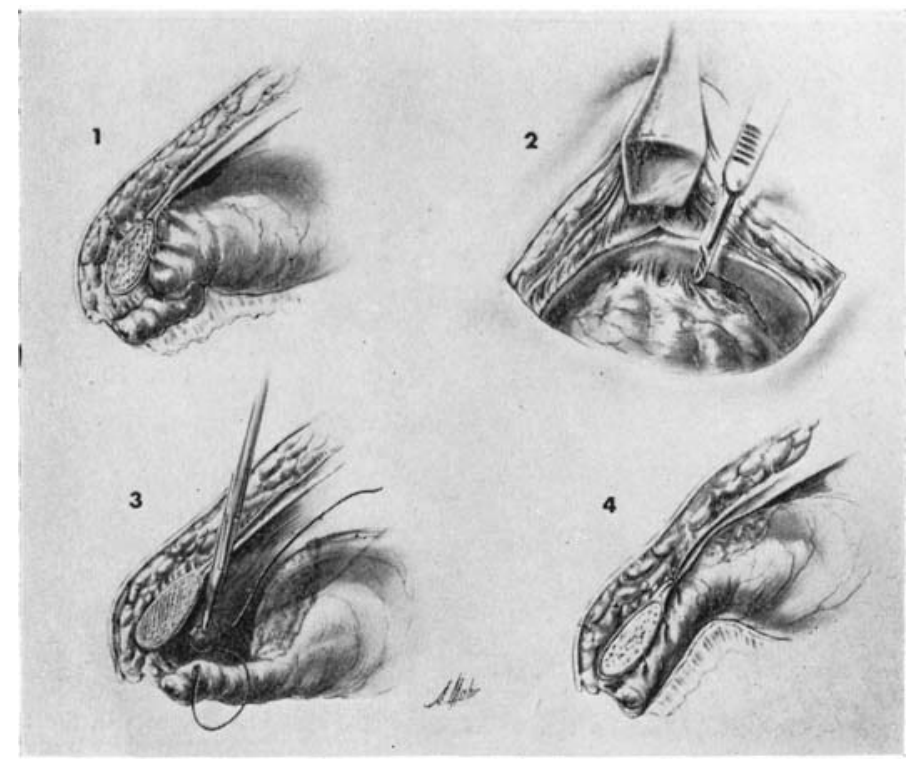

FIG. 8

Persistence of incontinence following the Marshall-Marchetti procedure is usually due to fixation of the urethra without elongation; this can be corrected by dissecting free the urethra and bladder and resuturing the urethra to the under side of the symphysis pubis with the urethra in an elongated position.

vaginal wall is intact, one approaches the urethra transvaginally by raising a vaginal flap (Fig. 9). The defective portion of the urethra is excised and the myo-elastic layer of the urethral wall approximated (Fig. 10). The repaired urethra is covered by replacing the anterior vaginal wall (Fig. 11).

If both the floor of the urethra and overlying vaginal wall are missing, the surgeon may find it necessary to make a combined suprapubic and transvaginal approach in order to achieve a satisfactory result. The purpose of the suprapubic approach is to obtain a rectus pedicle graft to interpose between the urethral and vaginal suture lines (Fig. 12, E to $\mathrm{H}$ ). In children the repair of a urethrovaginal fistula can best be accomplished by a suprapubic approach (Lapides, $1964 \mathrm{~b}$ ). Figure 12, A to $\mathrm{H}$, illustrates the various steps in restoration of the urinary sphincter in a 6-yearold child made incontinent following transurethral resection of the vesical neck.

At this point it would be well to pause and discuss the prophylactic treatment of urinary incontinence due to urethral defects. It has been our experience in recent years that many of the patients presenting with incontinence due to damaged urethras have sustained their lesions during transurethral resection of the vesical neck and urethra for various reasons. Although $m y$ 


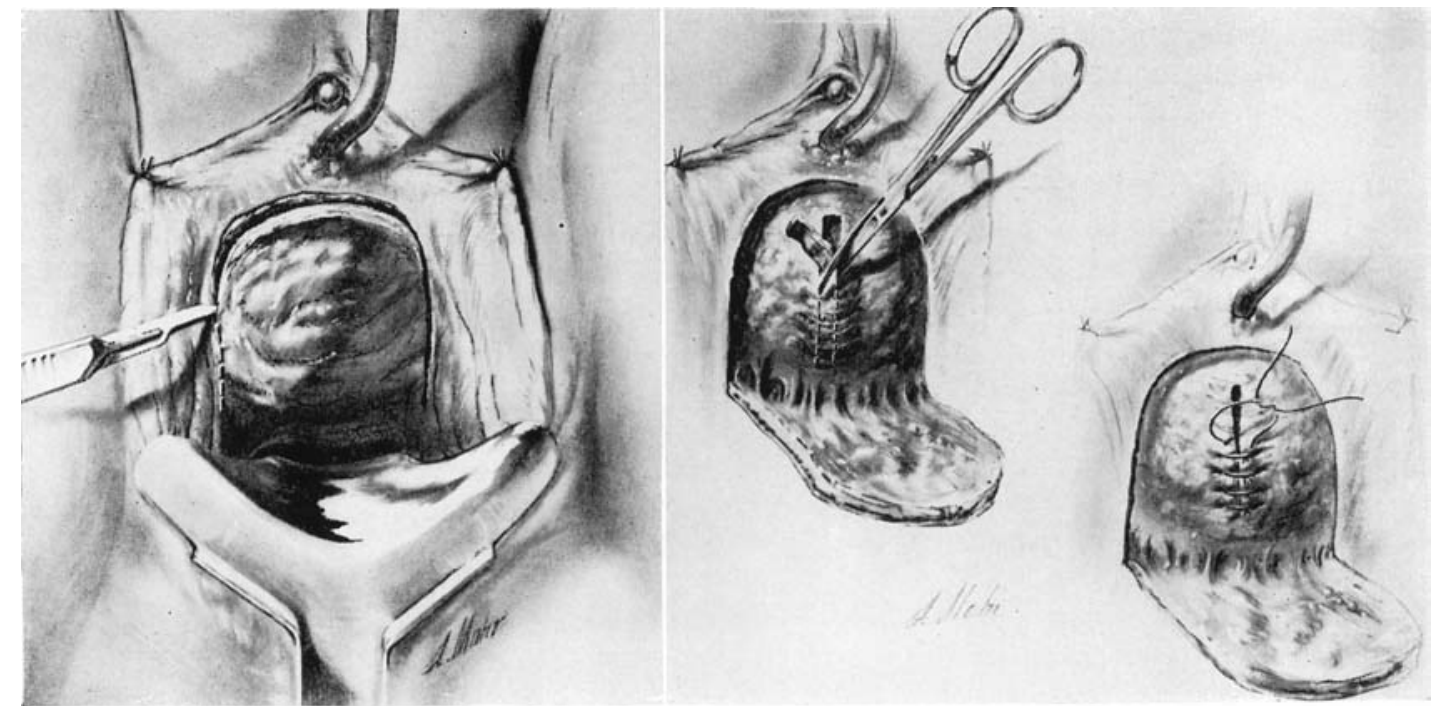

FIG. 9

FIG. 10

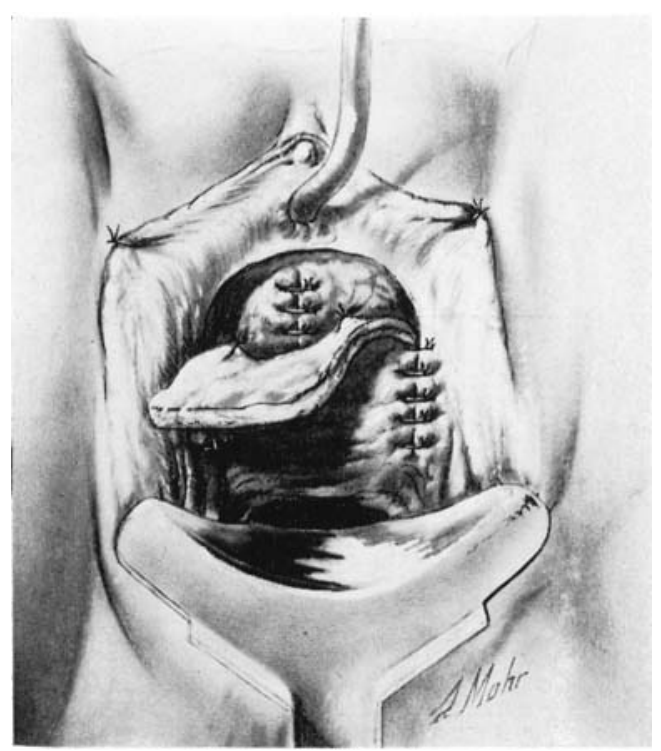

Figs. 9 to 11.--Defects in the floor of the urethra are repaired by transvaginal excision and reapproximation of normal urethral tissue.

colleague, Dr Reed M. Nesbit, and I are ardent advocates of the transurethral method of operation, we feel that there is no medical indication for the use of the resectoscope in the urethra of any female, young or old. It is pitiful and disheartening to contemplate the tragic total incontinence occurring in the child and young adult following transurethral resection of the normal urethrovesical junction and urethra for " urethrocystitis," "infected urethral glands," vesical neck contracture, post-operative urinary retention, " neurogenic bladder," etc. The urinary incontinence is indeed frequently tragic because the urinary sphincter or urethra has been so severely damaged that it 

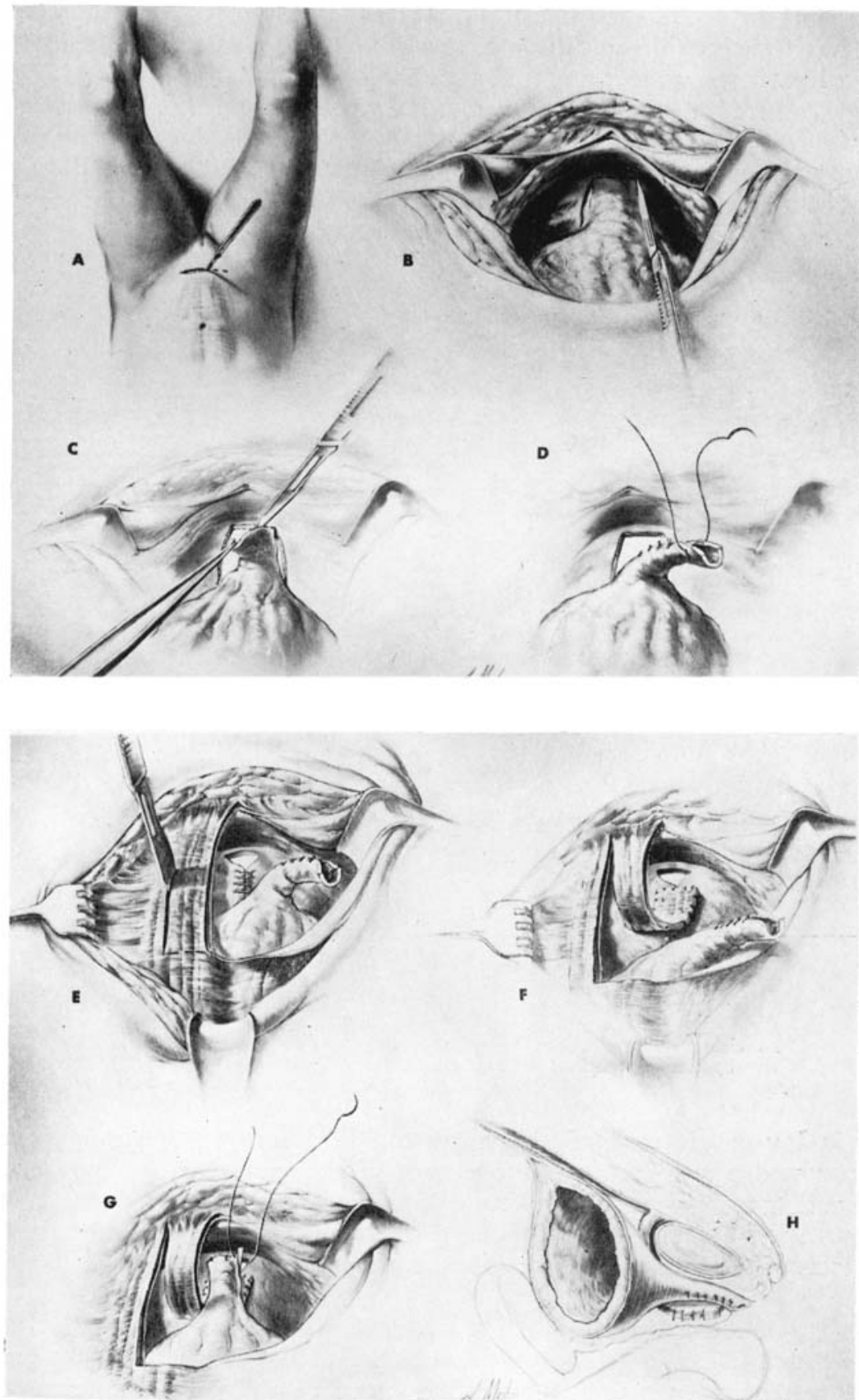

FIG. 12

Steps in the operative repair of the urinary sphincter of a child whose entire urethral floor and overlying vaginal wall necrosed following a series of iatrogenic incidents. 
cannot be reconstituted. This situation occurs when there has been a circumferential resection of the urethral wall for a considerable distance or when most of the urethra has sloughed following multiple transvaginal attempts to correct the original lesion caused by resection. Unfortunately, at the present time there is no satisfactory method of creating a functioning perineal neo-urethra from bladder wall.

Urinary incontinence in the obvious case of epispadias is treated by mobilising, resecting, and approximating the urethrovesical junction and urethra so as to form a narrow tube (Young, 1936).

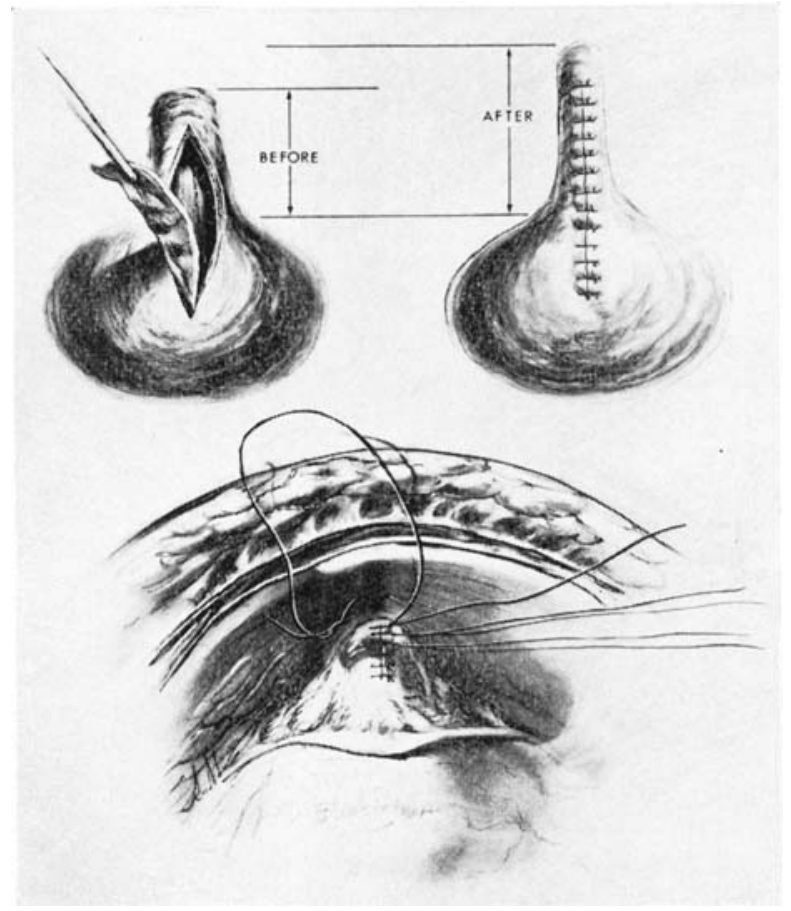

FIG. 13

Urinary incontinence in a patient with covert epispadias is treated by excising a diamond-shaped wedge of urethrovesical junction.

Incontinence in the covert case of epispadias can be improved considerably by excising a diamond-shaped wedge from the anterior surface of the urethrovesical junction and urethra, and reapproximating the margins of the wound so as to form a longer, narrower urethra (Fig. 13). Additional length and stability can be obtained by fixing the repaired urethra to the symphysis with the free ends of the sutures used to close the urethra (Fig. 13).

C. Drooping, Defective Urethra.- When a patient with a constant, dripping type of urinary incontinence is found to have a defect in the wall of the urethra associated with a decreased length of the urethra in the erect position, the treatment of choice involves a combined transvaginalsuprapubic approach (Lapides, 1961). After one raises a vaginal flap, the urethral defect is repaired. An anterior urethropexy is then performed and finally the vaginal flap is replaced.

If the patient with the drooping, defective urethra exhibits intermittent stress incontinence, it is best initially to perform only anterior urethropexy for, in many cases, this manœuvre will suffice in restoring normal incontinence. If the improvement is not sufficient, the surgeon can always perform the transvaginal excision of defective urethral wall at a later date. 


\section{DISCUSSION}

At the present time the major problem in the field of urinary incontinence is the patient with a urinary sphincter damaged sufficiently to prevent functional restoration of the organ by operative means. Neo-urethras constructed from bladder wall have not been very successful in the dependent perineal position. Experience gained from abdominal neo-urethras which have maintained satisfactory continence (Lapides, to be published) suggests that investigative efforts might be oriented toward creating a suitable periurethral striated muscle mass for the bladder tube. Urinary diversionary procedures remain the only certain means of establishing continence in these individuals.

\section{SUMMARY}

In the female the urinary sphincter is synonymous with the proximal three-fourths of urethra and is a tubular structure with a wall composed of smooth muscle and elastic tissue. The efficiency of the tube as a sphincter varies directly with the length of intact urethra.

Most cases of non-neurogenic urinary incontinence are due to a decrease in length of intact urinary sphincter. The shortened sphincter may be caused by a drooping of the urethra in the erect position, a defect in the wall of the urethra or by a defective urethra which droops.

Treatment incorporates restoration of normal length to the involved urethra by anterior urethropexy, excision of the urethral defect or by a combination of the two procedures. Posterior buttressing of the urethra and urethrocystopexies which do not lengthen the urethra are inadequate, unphysiological procedures for restoring urinary continence.

\section{REFERENCES}

LAPIDES, J. (1958), J. Urol., 80, 341.

- (1961). Brit. J. Urol., 33, 284.

- (1962). South. med.J., 55, 965.

- $(1964$ a). J. Urol., $91,658$.

- $(1964 b)$. J. Urol, , 91, 58.

Lapides, J., Ajemian, E. P., Stewart, B. H., Breakey, B. A., and Lichtwardt, J, R. (1960 a). J. Urol., 84, 86.

Lapides, J., Ajemian, E. P., Stewart, B. H., Lichtwardt, J. R., and Breakey, B. A. (1960 b). Surg. Gynec. Obstet., 111, 224.

Lapides, J., Friend, C. R., Ajemian, E. P., and Reus, W. F. (1962). J. Urol., 88, 245.

LYON, R. P., and SMITH, D. R. (1963), J. Urol., 89, 414.

Marshall, V. F., Marchetti, A. A., and Krantz, K. E. (1949). Surg. Gynec. Obstet., 88, 509.

WOODBURNe, R. T. (1960). J. Urol., 84, 79.

Young, B. W., and Niebel, J. D. (1958). J. Urol., 79, 838.

YounG, H. H. (1936). J. Urol., 35, 417.

Zimmerman, L. M., and Levine, R. (1964). "Physiologic Principles of Surgery." (Philadelphia and London: W. B. Saunders Co.) 